\title{
Democracia e sociedade de classes
}

O casamento entre a economia capitalista e um ordenamento político democrático é o figurino que define, ao lado dos arranjos familiares fundados na dominação masculina, a "estrutura básica" das sociedades ocidentais e o modelo que elas projetam para o resto do mundo ${ }^{1}$. Os mais entusiastas chegaram a ver, nesta combinação de capitalismo com democracia, o "fim da história", a organização social definitiva. Para o senso comum, para o discurso midiático e mesmo para boa parte da ciência social, é uma situação de fato, aceita nos seus próprios termos. É assim que, na maior parte das análises da ciência política, os constrangimentos impostos pelo capitalismo ao funcionamento dos regimes democráticos não são sequer tematizados.

De fato, o mainstream da disciplina acomodou-se plenamente ao entendimento da democracia que, tributário da virada schumpeteriana dos anos 1940, esforça-se por reduzi-la a um método de seleção de minorias governantes que nada, ou muito pouco, se conecta com uma ideia de so-

\ É professor do Instituto de Ciência Política da Universidade de Brasília (Brasília, DF), onde coordena o Grupo de Pesquisas sobre Democracia e Desigualdades, e pesquisador do CNPq. E-mail: Ifelipemiguel@ uol.com.br.

Este texto integra as pesquisas "Representação política, perspectivas sociais e representação simbólica" e "Desafios da teoria democrática numa ordem desigual", financiadas pelo CNPq com uma bolsa de Produtividade em Pesquisa e com recursos do edital no 20/2010, respectivamente. Agradeço os comentários de Regina Dalcastagnè e de Flávia Biroli. Versões iniciais foram apresentadas no II Simpósio de Ciências Sociais da Universidade Federal de Goiás, em Goiânia (novembro de 2011) e no Simpósio Nacional sobre Democracia e Desigualdades, em Brasília (abril de 2012); agradeço também as críticas e sugestões oriundas dos debates nesses dois eventos. 
berania popular. Uma "democracia domesticada" (Miguel, 2002a), em que os elementos de potencial atrito com a ordem capitalista foram eliminados.

A ressemantização sofrida pela palavra "democracia", para se acomodar a esse quadro, foi profunda. Mas o processo, como um todo, condiz com a tendência das correntes majoritárias das ciências sociais, em geral, e da ciência política, em particular, à reificação da realidade existente. $\mathrm{O}$ que causa espanto, por outro lado, é que, no campo das percepções críticas em relação às democracias realmente existentes, a discussão sobre as consequências desse casamento também esmaeceu. Até meados da segunda metade do século XX, os democratas radicais demonstravam uma consciência aguda de que o ideal democrático se ajustava mal a uma sociedade de classes e que as desigualdades promovidas pelo capitalismo geravam graves obstáculos à disseminação de práticas democráticas genuínas.

Basta lembrar, por exemplo, a obra de Carole Pateman (1992 [1970]) ou a de C. B. Macpherson (1978 [1977]), autores que identificavam, nas assimetrias de recursos materiais, de influência e de socialização entre trabalhadores e patrões, os principais obstáculos à realização das promessas da democracia. Mesmo entre autores liberais, tais problemas eram abordados. Robert Dahl, numa revisão de sua teoria pluralista, observava que o caminho para o aprofundamento da democracia passava necessariamente pela superação do capitalismo - segundo ele, na direção de alguma forma de economia autogestionária de mercado (Dahl, 1990 [1985]). Ou ainda Uma teoria da justiça, de John Rawls (1997 [1971]), em que se afirma de forma expressa que os caminhos para a construção de uma sociedade justa (o que inclui, necessariamente, um ordenamento político democrático) são ou o "socialismo liberal" ou um capitalismo de pequenos proprietários, com nítidos ecos rousseaunianos, no qual as principais desigualdades do capitalismo estariam dissolvidas e a igualdade de classes seria estabelecida ${ }^{2}$.

Hoje não é mais assim. Os problemas da relação entre capitalismo e democracia estão - quando muito - relegados à nota de pé de página, mesmo entre aqueles que se apresentam como herdeiros das tradições do pensamento "crítico". A vinculação aos valores mais substantivos da democracia, que a

\footnotetext{
A posição de Rawls é complexa e sofre evolução ao longo de sua obra. No entanto, é inegável sua preocupação com os efeitos da desigualdade de classes - que orienta, por exemplo, a avaliação de que - Welfare State não atende aos princípios da justiça, por permitir excessiva desigualdade no controle dos meios de produção (Rawls, 2001, p. 138).
} 
afastam da mera concorrência entre elites, como a igualdade e a autonomia, parece prescindir hoje de um enfrentamento com a diferença de classes.

Não se trata apenas de uma manifestação da tendência de extirpar o conflito do nosso entendimento da democracia, substituindo-o pela busca de consensos, tal como denuncia Mouffe (2005 [2000]). Afinal, mesmo as leituras consensuais da democracia reconhecem a existência de assimetrias sociais relevantes (de gênero, de raça etc.), que precisam ser enfrentadas. Mas, ainda nessa chave não conflituosa, as desigualdades próprias do capitalismo tomaram chá de sumiço.

Este artigo se organiza em três seções. Na primeira delas, busco sistematizar os principais fatores que levaram ao refluxo da crítica social centrada no conceito de classe, a partir do final do século XX. Na segunda, sustento que a ausência ou minimização das classes deixa uma grave lacuna na produção de qualquer teoria crítica da democracia. Na terceira, indico alguns dos motivos pelos quais a relação com o capitalismo é central para a compreensão dos limites da democracia contemporânea. Na conclusão, por fim, defendo uma teoria democrática que seja sensível à centralidade da desigualdade de classe (e ao conflito), mas sem ignorar a relevância de outras formas de opressão existentes na sociedade.

\section{Consenso e acomodação}

O refluxo da centralidade do conceito de classe, que ficou relegado a uma franja do pensamento político crítico, é explicado por movimentos paralelos - e evidentemente interligados - na realidade social e na reflexão teórica.

A queda do muro. Um claro ponto de partida é a derrota histórica dos projetos emancipadores da classe operária, tanto na sua vertente comunista quanto na sua vertente social-democrata. $\mathrm{O}$ colapso do mundo soviético, no final dos anos 1980, atingiu até mesmo os setores da esquerda que se opunham ao modelo stalinista. Pelo mundo afora, os partidos comunistas se extinguiram, se transformaram em partidos burgueses tenuamente reformistas ou se condenaram à irrelevância política ${ }^{3}$.

\footnotetext{
O caso mais emblemático é o do Partido Comunista Italiano, o maior partido comunista do Ocidente, propulsor da corrente "eurocomunista" crítica à União Soviética, que contava com o apoio de cerca de um terço dos eleitores da Itália. Em 1991, o PCI se transformou no Partido Democrático da Esquerda (PDS), que passou a ser, em 1998, o Democratas de Esquerda e, em 2007, por meio de fusão com outras agremiações, o Partido Democrático, já firmemente ancorado no centro do espectro político e sem a pretensão de representar a classe operária. A ala esquerda do PCI, insatisfeita com a transformação
} 
A derrocada da União Soviética também acelerou a crise da social-democracia e do modelo de capitalismo com bem-estar social por ela promovido - que, no entanto, possuía suas próprias raízes, vinculadas à chamada "crise fiscal do Estado" (O'Connor, 1973) ou, mais amplamente, às tensões entre as funções de acumulação e de legitimação (Offe, 1984 [1972]). Mas o fim do mundo comunista reduziu o espaço das opções reformistas nos países do Ocidente, reforçando a leitura de que a ameaça por ele representada contribuía, em alguma medida, para que a classe capitalista aceitasse políticas de apaziguamento do conflito distributivo. Sem a ameaça, a posição liberal recrudesceu e os partidos social-democratas caminharam rapidamente para a direita.

Embora a União Soviética estivesse longe de se constituir num modelo atraente, ela representava a indicação concreta de que a ordem econômica capitalista não era a única possível. Sem ela, o que resta são ou sobrevivências anacrônicas de um despotismo quase pessoal (Cuba, Coreia do Norte) ou a dominação autoritária do partido comunista combinada a uma economia cada vez mais capitalista (China). Em suma, há uma crença na inevitabilidade da ordem capitalista, ao menos em nosso horizonte histórico.

Diante disto, grande parte dos projetos transformadores optou por uma espécie de evasão ao enfrentamento da questão das relações de produção. As propostas da esquerda das últimas décadas têm privilegiado a busca do aprimoramento do convívio político, emblematizado em rótulos como "multiculturalismo" ou "democracia deliberativa”. Ainda que os debates lançados em torno destas propostas toquem em questões de grande importância, eles geram fracos substitutos para o socialismo, por deixarem de lado a questão-chave da economia política, como observou Nancy Fraser (1997, p. 2).

A crise do marxismo. Uma parte da explicação para essas mudanças está no avanço da crítica ao modelo monocausal de explicação do mundo social que caracteriza o marxismo. O caso do feminismo é, nesse sentido, exemplar. Para as feministas liberais, tratava-se simplesmente de franquear às mulheres, em condições de igualdade, acesso às mesmas posições que os homens na esfera pública, o que implicaria em reformulações profundas na organização da esfera doméstica. Mas uma parte importante do pensamento feminista colocou para si a tarefa de definir sua relação com o marxismo e com o problema das classes sociais.

em PDS, impulsionou a criação do Partido da Refundação Comunista, cuja votação oscila em torno de $5 \%$ do eleitorado italiano e que vive às voltas com sucessivas dissidências. 
Uma posição feminista tem necessariamente que romper a visão caricata de que o sexismo é uma mera consequência do capitalismo (ou, de maneira mais ampla, da dominação de classe) e que, portanto, a luta pela emancipação das mulheres já estaria incluída na luta pela emancipação do proletariado ${ }^{4}$. A afirmação da autonomia (ainda que "relativa") e da especificidade da questão feminina já se encontra em Alexandra Kollontai, no início do século XX. O que se coloca é como articular as formas de opressão e dominação baseadas em classe com aquelas baseadas em gênero, reconhecendo que possuem bases independentes, mas que se interpenetram.

As tentativas de formulação de uma homologia simplista, que apresentava a exploração da mulher pelo homem em termos similares à do trabalhador pelo patrão (ver Hartsock, 1998 [1983]), não se sustentaram. A dominação masculina não é uma variedade "doméstica" da dominação de classe, nem se define pela extração de sobretrabalho, ainda que ela certamente ocorra. Para a presente discussão, mais importante do que identificar as especificidades das diferentes formas de opressão e dominação é o entendimento de que a nossa sociedade é simultaneamente capitalista e "patriarcal"5. Se o feminismo dos anos 1980 alertava - de forma correta - que, sem atenção ao elemento "patriarcal", a compreensão do funcionamento do próprio capitalismo ficava comprometida, hoje talvez seja necessário lembrar que a análise da dominação masculina não pode ignorar o fato de que ela se dá numa sociedade capitalista.

${ }^{4}$ O mesmo se poderia dizer da luta contra o racismo, já que ele, em certas leituras marxistas, existiria apenas por ser funcional para a dominação sobre os trabalhadores. Ou seja, o socialismo seria a panaceia que eliminaria automaticamente todas as formas de opressão. Uma versão mitigada (e recente) do argumento reconhece que sexismo e racismo são anteriores ao capitalismo, mas secundários porque foram incapazes "de tecer e desenvolver no planeta um sistema social integrado e coordenado de interdependências" (Altamira, 2008 [2006], p. 27). No pensamento feminista, também se encontra por vezes a percepção de que o racismo é uma derivação do sexismo ou uma forma de "sexismo estendido" (Firestone, 1970, p. 108; ver tb. Millet, 1969; Daly, 1973; Chodorow, 1978). Para uma crítica, cf. Spelman (1988).

Uso o termo entre aspas porque julgo que ele é anacrônico. O patriarcalismo corresponde a um tipo específico de organização política, vinculado ao absolutismo, muito diferente das sociedades democráticas concorrenciais contemporâneas (cf. Elshtain, 1993 [1981], p. 215). O casamento contemporâneo ocidental tampouco se adequa ao figurino do patriarcado, sendo melhor entendido como uma"parceria desigual" (Fraser, 1997, p. 229), marcada pela maior vulnerabilidade das mulheres (Okin, 1989, p. 138-139). Em suma, instituições patriarcais foram transformadas, mas a dominação masculina permanece. E uma parte importante dessa transformação é a substituição de relações de subordinação direta de uma mulher a um homem por estruturas impessoais de atribuição de vantagens e oportunidades (Fraser, 1997, p. 234-235). Apenas na falta de uma alternativa suficientemente econômica, uso "patriarcal" para significar "estruturada pela dominação masculina". 
Um dos aspectos em que se marcou, com mais clareza, a necessidade de levar em conta as formas cruzadas de opressão social foi a recusa à ideia de uma identidade única dos grupos dominados. Feministas indicaram como aquilo que contava como a experiência da classe operária era a experiência dos homens da classe operária (ver, por exemplo, J. W. Scott, 1999 [1988]). Por outro lado, no seio do próprio feminismo se criticava a tendência a universalizar o ponto de vista das mulheres brancas de classe média (Spelman, 1988).

A crítica ao essencialismo decerto permanece, mas nela a classe nitidamente perdeu espaço para outras "diferenças". De fato, a desigualdade de classes se presta mal à celebração da diversidade humana, que é própria de muito do discurso sobre "as diferenças". A desigualdade de classes não é uma manifestação da diversidade de modos de ser que é capturada por uma estrutura social que os hierarquiza e submete uns a outros. É a expressão direta de uma assimetria no controle dos recursos materiais. Se há "diferentes tipos de diferenças", como diz Fraser (1997, p. 204), então a de classes certamente está no grupo das que deveriam ser abolidas numa sociedade justa - até porque a diferença de classe pode funcionar como impedimento ou obstáculo à expressão de outras diferenças ${ }^{6}$.

A cooptação do proletariado. Se uma parte da explicação para o recuo das classes tem a ver com a crítica ao modelo marxista de explicação monocausal, outra parte se liga a mudanças no panorama social do mundo capitalista desenvolvido, com a "acomodação" da classe operária à ordem vigente. $\mathrm{Na}$ leitura mais elaborada do fenômeno, a do filósofo francês André Gorz, os trabalhadores permanentes em tempo integral, que formam o núcleo central da classe operária, mas são a minoria da mão de obra nas economias desenvolvidas, tornaram-se capazes de manter um padrão de consumo relativamente elevado e usufruir dos serviços fornecidos por uma massa de trabalhadores precários (Gorz, 1988). O proletariado perde seu caráter revolucionário e se torna uma força social conservadora (Gorz, 1987 [1980]).

É importante observar que Gorz está analisando transformações na estrutura de classes dos países capitalistas centrais. Ele não adere à ideia de que as classes foram "superadas" (como faz, entre tantos outros, Rosanvallon, 1995). Pelo contrário, em que pese a aparente heterodoxia, sua análise é bem classicamente marxista, com a vinculação estreita entre a posição ocupada

Devo esta última observação a Flávia Biroli. 
nas relações de produção e o projeto político que aquele grupo social abraça ${ }^{7}$. E, embora pinte o novo papel conservador da classe operária em cores fortes, não há em Gorz a frustração do intelectual de esquerda contra os operários que não fizeram a revolução com que ele sonhava ${ }^{8}$.

Em muitas análises, há, de fato, uma confusão entre o reconhecimento da importância da análise de classes e a crença na missão emancipatória da classe trabalhadora. Afirmar a falência da segunda não implica descartar a primeira. É possível negar o caráter revolucionário do operariado, como faz Gorz, ou então recusar a noção de que projetos de transformação social estão necessariamente encarnados em determinadas classes sociais, e ainda assim admitir que a desigualdade de classes é central na estruturação das diferentes sociedades históricas e que a forma específica que essa desigualdade assume, no atual estágio do capitalismo, é crucial para o entendimento do mundo contemporâneo.

Os três elementos descritos até aqui correspondem, em linhas gerais, à crise da visão de uma sociedade alternativa ao capitalismo que se fundasse "na centralidade ontológica da classe operária, na afirmação da Revolução como momento fundacional [...] e na ilusão da possibilidade de uma vontade coletiva perfeitamente una e homogênea que tornaria inútil o momento da política” (Laclau e Mouffe, 1987 [1985], p. 2). É curioso observar que essa ilusão - que era projetada para a sociedade futura, em que as bases do conflito estariam superadas - ressurge na idealização de uma política organizada em torno dos valores do consenso, negadora, portanto, daquilo que ela possui de efetivamente político.

Repulsa ao conflito. O refluxo da influência do marxismo, desencadeado, em grande medida, pela crítica a insuficiências reais em seu arcabouço teórico, associou-se ao paulatino avanço, mesmo entre as correntes "críticas" de pensamento, de modelos idealistas e com ojeriza ao conflito. O mais influente

\footnotetext{
Falando da posição do marxismo mais ortodoxo, Ellen Meiksin Wood critica Gorz por "uma tendência a buscar a essência de um modo de produção no processo técnico do trabalho mais do que nas relações de produção" (Wood, 1998, p. 16). Creio que é uma leitura incorreta, que ignora que o projeto de Gorz passava por demonstrar uma vinculação estreita entre as técnicas produtivas e a dominação de classe. Mas, acima de tudo, é uma questão deslocada: não está em questão a busca de alguma "essência", mas a identificação da dinâmica do conflito social, em uma formação social concreta.

8 O maior exemplo é certamente Jean-François Lyotard, com sua denúncia do "gozo masoquista" do operariado com a exploração pelo capital (Lyotard, 1974). Não custa lembrar que qualquer ação revolucionária, com os riscos que acarreta, é um luxo raras vezes disponível para as classes dominadas (J. C. Scott, 1985).
} 
deles é, certamente, a busca do consenso comunicativo racional, de inspiração habermasiana. Ainda que não se possam universalizar as críticas às aplicações da obra de Habermas à teoria democrática, que são diversas e variadas, um ponto de partida comum é a ideia de que os atos de fala possuem características intrínsecas que fazem com que o consenso seja seu télos subjacente. E de que, como a razão se opõe ao interesse, mecanismos que forcem privilegiar a argumentação racional na esfera pública contribuirão para promover o bem comum, deixando em segundo plano os interesses particularistas ${ }^{9}$.

Partindo de uma matriz diferente, a teoria de John Rawls também postula que por meio da razão é possível transcender o conflito e chegar a uma ordem social consensualmente aceita. Seja pelo recurso a uma imaginária "posição original”, na qual estariam suspensos os interesses vinculados às diferentes situações na sociedade (Rawls, 1997 [1971]), seja pelo estabelecimento de um "consenso sobreposto de doutrinas razoáveis" (Rawls, 2000 [1983]), as bases de uma sociedade bem ordenada não estariam sujeitas a divergência. Ainda que Rawls se esforce para afirmar o contrário, seu desenho da sociedade bem ordenada elimina a política, substituindo-a pela mera "administração das coisas" (cf. Mouffe, 2005 [2000], p. 29).

Habermas e Rawls, assim, são as duas principais matrizes da tendência a apresentar o conflito como uma patologia a ser eliminada e a exilar os interesses do entendimento da dinâmica da política ${ }^{10}$. Chantal Mouffe observa, com razão, que a especificidade da política é eliminada e ela se torna um ramo ou uma aplicação da ética ou da moral (ver Mouffe, 2005 [2000], 2005). O fato de que a construção teórica da própria Mouffe não escapa de uma conciliação com o ideal do consenso - por meio de sua diferenciação entre o inimigo e o adversário, entre o "antagonismo" que deve ser contido e o "agonismo" que deve ser estimulado - é uma demonstração cabal da força desta démarche no pensamento político atual ${ }^{11}$.

A participação local. Por fim, é necessário observar que, dissipadas as esperanças no surgimento de algum tipo de sociedade pós-capitalista, há

9 Para uma crítica mais detida, cf. Miguel (2002b).

10 As principais, mas não as únicas. Seria possível incluir a "sociedade de risco", de Beck, e sua correlata próxima, a "sociedade reflexiva", de Giddens, como faz Mouffe (2005, cap. III). Ou, ainda, a teoria de Honneth, que, embora fale em /uta pelo reconhecimento, vê o conflito como sintoma, a ser superado, de um processo deficiente de integração social (cf. Honneth, 2003 [1992]).

"Ela chega a defender seu modelo "agonístico" como o único capaz de efetivamente evitar o antagonismo na política (cf. Mouffe, 2005, p. 4). 
uma espécie de euforia compensatória em torno de modelos localizados e limitados de participação popular. O Brasil ocupa uma posição de vanguarda, dada a "experimentação democrática" aberta após a Constituição de 1988 - orçamentos participativos, conselhos gestores de políticas públicas, conferências etc.. Embora a literatura, hoje, tenha em grande medida superado o tom acrítico e laudatório de muito do que se produziu nos anos 1990, permanece a aposta de que nessas "novas arenas participativas" se concentram as melhores possibilidades de transformação social ${ }^{12}$.

Sem avançar um diagnóstico que dissipe as diferenças entre essas experiências e também sem negar que muitos desses espaços podem contribuir positivamente para o arejamento das instituições representativas, é possível observar suas limitações. Duas delas são importantes, no âmbito da presente discussão. Não há um projeto transformador, na medida em que tais arenas têm foco em questões específicas e, para operar, precisam considerar como dada a institucionalidade vigente. E o conflito distributivo é traduzido, frequentemente, numa disputa pelo controle dos recursos do Estado, desinflando a preocupação com as causas estruturais da desigualdade e com o próprio conflito entre capital e trabalho.

\section{Céu e terra}

A ausência das classes no pensamento "crítico" sobre a democracia nos deixa, uma vez mais, com uma teoria que projeta um "céu político" desancorado de sua base material, conforme dizia Marx (2010 [1844]). A questão judaica dialoga com Bruno Bauer, mas a denúncia dessa falta de vinculação entre o mundo material e a política é dirigida, muitas vezes, ao pensamento liberal. A afirmação da igualdade de direitos entre os indivíduos - direitos que por vezes são acompanhados de adjetivos tão altissonantes quanto "inalienáveis" - é acompanhada de uma absoluta despreocupação com as bases que possibilitam o usufruto de tais direitos.

No pensamento de Locke, tal manobra é transparente. O contrato social visa garantir os direitos naturais que estão ameaçados no estado de natureza, em particular o direito de propriedade que, na definição lockeana, inclui também o direito à vida e à integridade física. No momento seguinte, porém, trabalhadores e mulheres são afastados da esfera pública. Os contratos de

12 Ver, por exemplo, os artigos reunidos em Avritzer (org., 2011). 
trabalho e de casamento sacramentam relações de subordinação pessoal que seriam incompatíveis com o exercício dos direitos políticos. Ao mesmo tempo, na visão de Locke, esses dois contratos sinalizam a racionalidade inferior tanto de mulheres quanto de trabalhadores, que precisam se colocar sob a tutela de outros. Assim, a exclusão é tanto o efeito de contratos livremente firmados quanto a consequência de uma incapacidade natural; e trabalhadores e mulheres devem se colocar voluntariamente na posição de submissão à qual estão destinados por natureza (cf. Pateman, 1993 [1988]). No liberalismo de Locke, a afirmação inicial da universalidade dos direitos é seguida pela explicitação de que alguns não poderão exercê-los.

É evidente que essa explicitação está ausente do discurso mais contemporâneo. Mas a separação entre o direito e as condições de usufruto permanece como um elemento central do pensamento liberal. Uma elaboração sofisticada da questão está na distinção entre "liberdade negativa" e "liberdade positiva", tal como formulada por Isaiah Berlin (1969). Enquanto a primeira se refere à ausência de coerção externa, em particular a coerção estatal, nas decisões sobre a própria vida, a segunda envolve a participação no autogoverno coletivo. Trata-se, como se vê, de uma reciclagem da velha oposição entre a liberdade dos antigos e a dos modernos, em linha bastante congruente com a célebre argumentação de Benjamin Constant, no começo do século XIX. Berlin não nega valor à liberdade positiva, que reconhece como um ideal digno de respeito. Mas confere uma primazia lexicográfica à liberdade negativa. Com isso, o autogoverno - a esfera da igualdade de direitos - fica limitado pela intocabilidade da autonomia individual privada, isto é, da esfera em que o exercício da liberdade é condicionado pelos recursos diferenciados disponíveis para os indivíduos.

Uma versão bem menos sofisticada do argumento, portanto bastante mais clara, é encontrada na obra de Hayek. Em sua crítica à ideia de que há necessidade de uma base material mínima para o gozo da liberdade, ele diz:

É importante perceber a sutil alteração de sentido a que se submeteu a palavra liberdade para tornar plausível este argumento. Para os grandes apóstolos da liberdade política, essa palavra significava que o indivíduo estaria livre da coerção e do poder arbitrário de outros homens, livre das restrições que não lhe deixavam outra alternativa senão obedecer às ordens do superior ao qual estava vinculado. Na nova liberdade prometida, porém, o indivíduo se libertaria da necessidade, da força das circunstâncias 
que limitam inevitavelmente o âmbito da efetiva capacidade de escolha de todos nós, embora o de alguns muito mais do que o de outros. [...]

Liberdade neste sentido não passa, é claro, de um sinônimo de poder ou riqueza (Hayek, 1990 [1944], p. 49).

Trata-se exatamente disso - ou quase. A crítica à visão estritamente negativa da liberdade passa pelo entendimento de que um conceito robusto de liberdade envolve necessariamente elementos materiais, o "poder ou riqueza" que estão na base de toda ação humana. A vulnerabilidade à "coerção e poder arbitrário de outros homens", como diz Hayek, não pode ser limitada à autoridade política estatal sob pena de perdermos de vista a dinâmica real da dominação e da resistência na sociedade.

Com isso, não se deseja voltar à denúncia, própria de certa ortodoxia marxista, dos "direitos formais burgueses". O descompasso entre a fixação de direitos e a possibilidade de exercê-los de forma efetiva não significa que a existência de direitos é irrelevante. No mínimo, os direitos "formais" delimitam um ideal socialmente aceito e legitimam valores igualitários - em vez de denunciá-los como vazios, é possível tomá-los a sério e exigir que a ordem social os realize (Mouffe, 1992, p. 2). Além disso, mesmo que a possibilidade de desfrutá-los seja distribuída de forma assimétrica, as brechas que eles abrem para diversas formas de ação não são desprezíveis.

O direito de voto serve de ilustração. A conquista do sufrágio universal masculino enfrentou fortes resistências da classe dominante. O medo - espelhado nas esperanças de muitos socialistas do século XIX - era de que as classes trabalhadoras ou, mais genericamente, os pobres transformassem sua inequívoca vantagem numérica em poder político e promovessem uma redistribuição radical da riqueza e da propriedade. Mesmo um liberal progressista e esclarecido, como John Stuart Mill, que defendia o sufrágio universal (incluindo até as mulheres), julgava necessário temperá-lo com um sistema de pesos que sobrerrepresentaria os mais ricos e instruídos (Mill, 1995 [1861]).

Como bem sabemos, o voto não gerou tais consequências. As vantagens dos grupos dominantes na organização de seus interesses políticos continuaram a se fazer sentir, até mesmo nos momentos eleitorais. Pode-se dizer que o modelo liberal de eleição, em que cada cidadão é chamado a participar isoladamente, dentro de um quadro normativo de "votar com a própria consciência”, privilegia a expressão de interesses individuais, em detrimento 
daqueles que precisam ser construídos coletivamente, na linha do que diziam Offe e Wiesenthal (1984 [1980]). E ainda que a concessão do direito de voto deslegitimou, automaticamente, outras formas, mais ofensivas, de expressão política popular, como observou Albert Hirschman. Afinal, por que fazer manifestações de rua, motins ou barricadas, se as demandas podem ser apresentadas por via eleitoral (Hirschman, 1983 [1982], p. 121-126)?

Assim, o sufrágio universal não concretizou de fato a igualdade que prometia, emblematizada na divisa "uma pessoa, um voto". No entanto, ele reafirma, normativa e simbolicamente, a igual consideração devida a todos os cidadãos e a todas as cidadãs, a seus interesses e opiniões. Obriga a que os grupos sociais dominados sejam levados em conta no processo de tomada de decisões e pode permitir, como por vezes ocorre, que o jogo político dos dominantes seja desorganizado por surpresas que vêm de baixo.

Os direitos importam. Mas não bastam. Já que evoquei Locke no começo da seção, caminho agora um pouco com Rousseau. Para ele, o problema a ser enfrentado pelo contrato social é a geração de uma liberdade e uma igualdade convencionais que repliquem a liberdade e a igualdade naturais, perdidas ao se deixar o estado de natureza. Mas a fixação da convenção não esgota a resolução do problema. A vigência da democracia depende de uma relativa igualdade de meios; na fórmula famosa, "que nenhum cidadão seja tão opulento que possa comprar outro e nenhum tão pobre que se veja constrangido a se vender" (Rousseau, 1964 [1757], p. 391-392).

Hannah Arendt observa que, no pensamento grego, a igualdade era um atributo da pólis, não dos homens. Era uma virtude da condição de cidadão, que se sobrepunha a uma natureza humana percebida como desigual (Arendt, 2011 [1963], p. 59). Nossa noção predominante de direitos, por sua vez, tende a relacioná-los à ideia de uma igualdade, senão de méritos e talentos, ao menos de dignidade entre todos os seres humanos. Rousseau nos ajuda a lembrar que o aproveitamento desses direitos, portanto a afirmação efetiva da igual dignidade de todos, depende de condições que não podem ser pressupostas a priori.

Todo esse longo e acelerado percurso, que em poucos parágrafos nos levou de Locke e Berlin a Rousseau e Arendt, visava chegar a esta conclusão: a organização social explicitada nas normas de uma sociedade só é dotada de pleno sentido quando conectada com as circunstâncias reais de vida das mulheres e homens que a habitam. Nenhuma teoria que permaneça presa ao 
"céu" dos ordenamentos abstratos, sem atenção às disparidades no controle dos diferentes recursos (materiais, informacionais, cognitivos, culturais, organizacionais, simbólicos), será capaz de fazer uma crítica consequente das sociedades contemporâneas.

Junta-se a isso a prevalência de uma postura de negação ou subestimação do conflito como elemento fundador da política, já referida na seção anterior. É possível identificar, em muito da valorização das diferenças enquanto diferenças, nas correntes "progressistas" do pensamento contemporâneo, a "típica ilusão liberal de um pluralismo sem antagonismo", como diz Mouffe (2005 [2000], p. 20). Mas o antagonismo está presente porque as diferenças estão intimamente ligadas a relações de dominação - que as atravessam ou, em muitos casos, as produzem. Caso se aceite que os conflitos vinculados às diversas relações de dominação devem ocupar posição de destaque em qualquer descrição da dinâmica social, então não é possível negar centralidade à desigualdade de classe, como um dos eixos desses conflitos.

\section{Capitalismo e os limites da democracia}

É inegável que, nas últimas décadas, não há nenhum ordenamento social que se apresente como alternativa viável ao capitalismo. A tese de um "fim da história" foi barulhentamente aventada com a queda do muro de Berlim - o casamento entre capitalismo e democracia concorrencial seria a forma definitiva de organização do mundo social e, na ausência de qualquer grande evento transformador, de qualquer batalha social ou política, nós estaríamos fadados a levar uma "vida de cachorro", que consistiria em comer e dormir (Fukuyama, 1992). Hoje, nem o próprio Fukuyama acredita nessa ideia. Mas, mesmo que ela fosse correta, mesmo que não fosse possível produzir nenhuma alternativa ao capitalismo, isso não nos autorizaria a negar a continuada relevância dos limites que a ordem capitalista impõe à democracia.

A compreensão tradicional de democracia vinculava-a fortemente à igualdade entre os cidadãos (ainda que o preço a pagar fosse excluir muitos grupos do acesso à cidadania). É algo central na concepção clássica - de onde herdamos tanto a palavra quanto o imaginário associado a ela - e que prossegue, pelo menos, até os séculos XVIII e XIX. A igualdade define a natureza da democracia para Montesquieu; é a condição que a permite, para Rousseau, como já visto. E mesmo Tocqueville usa "igualdade" e "democracia" como termos intercambiáveis, quase sinônimos, em seu A democracia na América. 
É bem verdade que Tocqueville, falando da posição da aristocracia em declínio, tende a focar na igualdade de status e a ver como secundárias as desigualdades materiais. Seu uso de "igualdade de condições" não corresponde precisamente àquilo que a expressão evoca nos debates contemporâneos. Ainda assim, suas páginas eloquentes sobre o amor democrático pela igualdade - que chega a tomar a forma de um goût depravé, um gosto depravado (Tocqueville, 1992 [1835], p. 59) - soam surpreendentes para quem tem em mente as democracias do século XXI.

O passo fundamental na conciliação entre democracia e desigualdade foi o esvaziamento do sentido da primeira, que paulatinamente se reduz a um método de escolha concorrencial dos governantes - e não mais a um "governo do povo" -, que se pode descrever como um mercado político, homólogo ao mercado econômico. O ponto de virada, claro, foram os poucos capítulos dedicados ao tema por Joseph Schumpeter em seu Capitalismo, socialismo e democracia (1942). Genial como descrição legitimadora do regime político dos países ocidentais, a ressemanticização inspirada em Schumpeter cindiu em duas a própria apreensão de senso comum sobre a democracia, que hoje remete simultaneamente à soberania popular e à competição entre elites.

É com o entendimento mais robusto de democracia em mente, aquele que enfatiza a possibilidade de autonomia coletiva, no entanto, que se podem identificar as severas limitações que a ordem econômica capitalista impõe a seu florescimento. Os três itens que desenvolvo brevemente a seguir chamam a atenção por sua obviedade. Trata-se exatamente disto: de reafirmar o que é evidente e argumentar que ele merece consideração nas reflexões críticas sobre a sociedade atual.

Dependência estrutural. O monopólio dos proprietários privados sobre as decisões de investimento, que é um dos traços definidores do capitalismo, coloca o Estado na dependência de suas decisões. Afinal, o Estado sobrevive da arrecadação de impostos, que reflete o nível de atividade econômica, que, por sua vez, reflete o nível de investimento. Com isso, os governantes - independentemente de suas simpatias políticas - precisam introjetar os interesses do capital, garantindo uma situação que estimule a manutenção de taxas elevadas de investimento econômico (Offe, 1984 [1972]) ${ }^{13}$. Não é

\footnotetext{
${ }^{3}$ Políticas de tipo keynesiano, pelas quais o Estado assume a tarefa de induzir o investimento, servem de confirmação para essa afirmação. O que se diz não é que o Estado não interfere na atividade econômica, mas que sua interferência se faz tomando como dado inegociável a necessidade de valorização do capital.
} 
necessária nenhuma conexão especial com a elite política, nem a apresentação de algum tipo de chantagem ou ameaça por parte da classe capitalista; a estrutura econômica garante que seus interesses receberão uma atenção privilegiada por parte dos detentores do poder de Estado.

Isso significa uma redução do escopo da soberania popular. Estão bloqueadas medidas que afetem os níveis de remuneração minimamente aceitáveis para o capital, que gerariam uma retração da atividade econômica que colocaria em risco todas as ações governamentais. Tais níveis variam de acordo com as circunstâncias, pois

a posição de força dos empresários ou dos investidores inclui a capacidade de definir a realidade. Isto significa que aquilo que eles consideram como uma carga [de impostos] insuportável é efetivamente uma carga insuportável, que conduzirá, nos fatos, a uma queda da propensão a investir [...]. O debate sobre o fato de saber se o Estado "realmente" reduziu os lucros é, por esta razão, puramente acadêmico, pois os investidores estão em posição de realmente poder produzir, por suas próprias interpretações, um "estrangulamento do lucro" e os efeitos que o seguem (Offe, 1997 [1984], p. 84-85; ênfases suprimidas).

O que permite que decisões com tão evidente impacto coletivo permaneçam ao arbítrio de indivíduos privados é a separação entre economia e política como duas esferas distintas. Como bem demonstrou Ellen Meiksin Wood, essa divisão, na forma como nós hoje lemos como "natural", foi produzida pelo próprio capitalismo. Com ele, há a privatização das funções sociais de produção, distribuição, extração de mais-valia e apropriação, gerando uma esfera econômica diferenciada. A apropriação e a exploração capitalista transformam certas questões políticas essenciais, disputas sobre exploração e dominação antes ligadas ao poder político, em questões econômicas. Em suma, a diferenciação do econômico e do político no capitalismo é a diferenciação de atividades políticas em si, alocadas separadamente na esfera econômica privada e na esfera pública do Estado (Wood, 1995, p. 31).

Influência "pervasiva" do poder econômico. As desigualdades de riqueza, que são resultado inevitável e esperado da dinâmica capitalista, tendem a se manifestar em todas as esferas sociais. Elas são "pervasivas", para usar um anglicismo necessário - permeiam tudo, infiltram-se em todas as relações sociais. E o campo político é particularmente suscetível à influência do poder econômico. 
Um momento em que essa influência se manifesta com absoluta clareza é o das eleições. Os financiadores de campanha - empresas ou empresários - são atores centrais do jogo eleitoral; a capacidade de cortejá-los é item indispensável a quem deseja ascender às posições políticas de maior destaque. Riqueza se converte facilmente em crédito político.

Mesmo a campanha de Barack Obama à presidência dos Estados Unidos, em 2008, que é muitas vezes apresentada como exemplo de um novo padrão de financiamento político, revela a permanência da importância dos grandes contribuidores. Milhões de eleitores estadunidenses doaram pequenas quantias, de duzentos dólares ou menos, que, no entanto, somaram apenas 26\% do quase meio bilhão de dólares que custou a campanha de Obama nas primárias do Partido Democrata e, depois, nas eleições (Malbin, 2009, p. 4). Num gesto amplamente divulgado, o candidato Obama abriu mão do financiamento público, não do dinheiro dos grandes doadores.

Ainda que fosse a única fonte de recursos, a "pequena" contribuição individual sinalizaria uma ruptura com a regra democrática de igualdade de influência política. Cada cidadã ou cidadão tem um único voto, com peso idêntico, mas quem contribui com vinte dólares ou reais vale o dobro de quem contribui com apenas dez. Uma leitura generosa pode tentar ver, aqui, um espaço para expressão das diferentes intensidades de preferências, às quais o mecanismo eleitoral é notoriamente insensível. Mas a conclusão é insustentável. A utilidade marginal dos reais ou dólares despendidos no financiamento eleitoral é uma função inversa da riqueza de cada um. Assim, os mais ricos pesam mais - porque contribuem mais - mesmo com preferências menos intensas.

Em muitos países, a legislação tenta reduzir a influência do poder econômico nas campanhas eleitorais, com menor ou maior rigor. A medida mais extrema é a proibição total de qualquer contribuição privada, com o financiamento público exclusivo. Mesmo se uma regra desse tipo funcionasse sem falhas, o que está longe de ser garantido, a disparidade no controle dos recursos materiais permaneceria se fazendo sentir na esfera política.

Numa ponta, a privação material retira os recursos básicos para a ação política, tais como o acesso à informação e o tempo livre. Na outra, a influência da riqueza possui impactos que superam, e muito, o financiamento da campanha. Antes das campanhas propriamente ditas, o capital econômico já desempenha um papel fundamental na produção da "saliência" social - a 
possibilidade de individualização em meio ao público geral - que é tão importante na viabilização da liderança política, como observou Manin (1999, p. 142-144). Depois dela, pavimenta caminhos de acesso aos funcionários eleitos, como também às burocracias permanentes, por meio de diferentes procedimentos de lobby.

E, ainda mais importante, em todas as fases do processo político - antes, durante e depois das eleições -, há o fato de que o capital influencia fortemente o fluxo de informações, dado que a mídia é, ao menos parcialmente, organizada na forma de empresas comerciais. O controle da informação significa a capacidade de determinar quais temáticas vão predominar na agenda pública, quais enquadramentos terão maior visibilidade, quais agentes serão os interlocutores do debate. Os "climas de opinião" assim produzidos impactam o resultado de eleições, em intervenções disruptivas da ordem política estabelecida e na tomada de decisões sobre questões controversas. A eleição de Fernando Collor, em 1989, a deflagração dos golpes militares no Brasil, em 1964, ou no Chile, em 1973, e a derrota do primeiro governo Clinton na reforma da saúde pública nos Estados Unidos, na metade dos anos 1990, são exemplos dessas diferentes formas de influência de campanhas de mídia.

Não se trata de dizer que os meios de comunicação controlam a política ou que o controle privado na mídia implica o silenciamento completo de perspectivas divergentes na esfera pública. A relação entre a mídia e a política está longe de ser de mão única (Miguel, 2002c) e o ambiente de informação é complexo, com entrelaçamentos entre emissoras comerciais, formas de comunicação pública, novas tecnologias e redes tradicionais (Biroli e Miguel, 2011). Mas os meios comerciais permanecem em posição central, por sua abrangência e penetração.

Socialização inadequada dos trabalhadores para a ação política democrática. Por fim, cabe observar que, sob relações de produção capitalistas, os trabalhadores recebem um treinamento que privilegia qualidades opostas àquelas exigidas para a prática da democracia. O contrato de trabalho submete o assalariado a uma relação vertical, em que seu papel é obedecer a ordens emanadas de seu empregador ou de seus prepostos. Isto é, o trabalho assalariado coloca os trabalhadores em situação de radical heteronomia. É o contrário da participação engajada na busca de soluções e da responsabilidade pelas próprias escolhas que caracterizaria, idealmente, os cidadãos e as cidadãs de uma democracia (Pateman, 1992 [1970]). 
Se no local de trabalho o autoritarismo das relações representa um mau treinamento para a democracia, fora dele há outros constrangimentos que o afetam. Nas economias capitalistas contemporâneas, o trabalhador é tanto um produtor quanto um consumidor. O consumo de massa é vital para o funcionamento da economia - e é alimentado por um estímulo constante à ideia de consumo como meio de realização pessoal e também como compensação por frustrações em outros âmbitos, a começar pela própria produção (Gorz, 1988). O discurso de valorização da esfera privada é a contraface da estrutura que bloqueia os espaços de participação efetiva na esfera pública.

Em suma, qualquer tentativa de entender como são produzidos os interesses políticos - e também o interesse pela política - deve se debruçar sobre os padrões de socialização e sobre os incentivos diferenciados que partem do campo político e das estruturas sociais (Bourdieu, 1979). A afirmação abstrata da igualdade de participação ou a crença, que muitas vezes vem de contrabando, de que os diferenciais de envolvimento político são fruto de disposições individuais diversas elidem a questão essencial da fabricação social da presença política, na qual as relações de trabalho e consumo são um elemento significativo.

\section{Conclusões}

A junção entre capitalismo e democracia envolve a acomodação entre esta última e a desigualdade econômica. A capacidade de mobilização e de influência política está ligada ao controle de recursos materiais; sua distribuição excessivamente assimétrica viola o princípio de igualdade política que é básico na democracia.

Parte dos problemas tem a ver com os padrões diferenciados de socialização dos indivíduos, de acordo com a posição nas relações de produção. Trabalhadores devem obedecer a ordens emanadas de seus patrões. Não têm incentivo para desenvolver habilidades de discussão e negociação, nem para ampliar seus horizontes para além de sua atividade laboral. Suas habilidades políticas precisam se desenvolver fora do e contra o espaço do trabalho.

Há também a parte que reflete a posição estrutural do capital, que faz com que seus interesses sejam mais diretamente cruciais para o Estado do que os interesses do trabalho. A remuneração do investimento deve ser alta o suficiente para que os proprietários prefiram reinvestir, em vez de dilapidar 
o capital ou - alternativa cada vez menos custosa, em tempos de mundialização - transferi-lo para outro local.

Como observou Przeworski, democracia e mercado são mecanismos concorrentes de alocação de recursos. No mercado, as pessoas têm pesos desiguais, de acordo com aqueles recursos que já controlam. Suas decisões, embora possam vir a ter impactos indiretos significativos, afetam, em primeiro lugar, esses mesmo recursos. Na democracia, as pessoas possuem peso igual e expressam preferências relativas a recursos que não controlam privadamente. "Só por mágica os dois mecanismos podem levar a um mesmo resultado" (Przeworski, 1995 [1990], p. 7).

É possível defender a tese de que, diante desses dois mecanismos concorrentes, o mercado é superior à democracia. É o que faz toda a linhagem ultraliberal. Hayek denuncia o apreço excessivo pela democracia, afirmando que ela é apenas um instrumento para a proteção da liberdade - que, para ele, se realiza no mercado (Hayek, 1990 [1944]). Nozick, com um de seus engenhosos silogismos, tenta provar que a democracia é simplesmente uma forma de escravidão diante da coletividade (Nozick, 1974, p. 290-292). Para David Friedman, decisões democráticas são homogeneizadoras, ao passo que o mercado garante o florescimento da diversidade (Friedman, 1989 [1973]).

Por mais equivocadas que sejam tais opiniões - que dependem de uma conceituação de liberdade que é cega aos constrangimentos materiais -, elas têm o mérito de afirmar abertamente o conflito potencial entre a democracia e o capitalismo. O que está em jogo, nessa discussão, é o valor da autonomia. O pensamento democrático traz o apelo normativo de que as regras que regem a vida em sociedade devem ser produzidas, coletivamente, por todos os que estarão submetidos a elas. Se decisões sobre uma esfera tão importante como a economia são monopolizadas por um pequeno grupo, então todo o projeto de autonomia coletiva está ameaçado.

A ideia de autonomia coletiva pode ser considerada inatingível, como diz Riker. As decisões coletivas são sempre potencialmente irracionais e passíveis de manipulação, o que ele demonstra por meio de uma série de modelos inspirados no paradoxo de Concorcet (Riker, 1982). Ou então pode ser considerada moralmente incorreta. É o argumento de Nozick, para quem o bem supremo é a autonomia individual, que, para ser resguardada, exige que as decisões sejam alocadas aos indivíduos privados. Seu célebre exemplo é o da mulher que decide com quem vai se casar. Sua decisão afeta todos os 
seus pretendentes, as pretendentes de seus pretendentes e assim por diante. Conclui-se que a regra de que devemos participar da tomada de decisões que nos afetam não pode ter validade (Nozick, 1974, p. 269).

Já se argumentou que os paradoxos de Riker dependem da redução da democracia a uma fórmula de agregação de preferências fixas e prévias. Se acrescentamos momentos de debate, de negociação e de construção de alternativas, as "impossibilidades" da democracia se desvanecem (Mackie, 1998). Quanto a Nozick, aqui, como em outros momentos, sua estratégia de reductio ad absurdum depende da indiferenciação entre espaços sociais - se uma regra vale para um, tem que valer para todos. É mais difícil manejar um modelo de pensamento que conceda lugar à intimidade e à publicidade, à participação e à autonomia individual etc.. Certamente as fronteiras nem sempre serão bem nítidas. Mas esse modelo lida melhor com uma realidade social complexa e nos permite distinguir entre um casamento e uma decisão de investimento. Uma simples diferenciação entre a pessoa e suas propriedades externas já dá acesso a essa distinção - mas ela também está fora do universo de Nozick.

A ideia de autonomia coletiva está no coração de qualquer compreensão normativamente íntegra de democracia. As desigualdades sociais significativas são aquelas que afetam o exercício dessa autonomia - e, dentre elas, a desigualdade de classe certamente ocupa uma das posições de destaque. É por isso que a ausência da preocupação com a desigualdade de classe retira das teorias "críticas" a capacidade de fazer uma análise consequente das democracias atuais. A suspensão da desigualdade de classe como problema não permite tratar adequadamente das condições em que a própria expressão das diferenças, como algo politicamente relevante, se torna possível ${ }^{14}$.

Não é necessário postular que a desigualdade de classe é mais profunda, mais grave ou mais determinante do que outras formas de desigualdade social, como aquelas baseadas em sexo ou em raça/cor. O importante é entender que essas diferentes formas de assimetria e opressão, embora tenham bases independentes - no sentido de que não são derivadas umas das outras, nem explicadas por sua funcionalidade para a reprodução de outras desigualdades - estabelecem uma transversalidade cruzada, em que seus efeitos se sobrepõem.

${ }^{14}$ Agradeço novamente a Flávia Biroli por este comentário. 
Hoje parece mais fácil visualizar uma sociedade sem sexismo, sem racismo ou sem homofobia do que uma sociedade pós-capitalista. Talvez seja por isso que a insistência na relevância das classes soe demodée ou que se diga que nada se ganha comprovando a incompatibilidade entre capitalismo e democracia, "além de um ataque agudo de depressão" (Phillips, 1999, p. 17). Ainda assim, ainda que seja mais para indicar dificuldades do que soluções, a advertência sobre esta relevância permanece válida para qualquer projeto de democracia que se pretenda fiel a seu caráter emancipatório.

\section{Bibliografia}

ALTAMIRA, Carlos (2008 [2006]). Os marxismos do novo século. Rio de Janeiro: Civilização Brasileira.

ARENDT, Hannah (2011 [1963]). Sobre a revolução. São Paulo: Companhia das Letras.

AVRITZER, Leonardo (org.) (2011). A dinâmica da participação local no Brasil. São Paulo: Cortez.

BERLIN, Isaiah (1969). “Two concepts of liberty”, em Four essays on liberty. Oxford: Oxford University Press.

BIROLI, Flávia \& MIGUEL, Luis Felipe (2011). "Razão e sentimento: a comunicação política e a decisão do voto". Paper apresentado no XX Encontro Anual da Associação Nacional de Programas de Pós-Graduação em Comunicação (COMPÓS). Porto Alegre (RS), 14 a 18 de junho.

BOURDIEU, Pierre (1979). La distinction: critique sociale du jugement. Paris: Minuit.

CHODOROW, Nancy (1978). The reproduction of mothering: psychoanalysis and the sociology of gender. Berkeley: University of California Press, 1978.

DAHL, Robert A. (1990 [1985]). Um prefácio à democracia econômica. Rio de Janeiro: Jorge Zahar.

DALY, Mary (1973). Beyond God the father: toward a philosophy of women's liberation. Boston: Beacon Press.

ELSHTAIN, Jean Bethke (1993 [1981]). Public man, private woman: women in social and political thought. 2. ed.. Princeton: Princeton University Press. FIRESTONE, Sulamith (1970). The dialectic of sex. New York: Bantam.

FRASER, Nancy (1997). Justice interruptus: critical reflections on the "postsocialist" condition. Nova York: Routledge. 
FRIEDMAN, David (1989 [1973]). The machinery of freedom: guide to a radical capitalism. 2. ed. Chicago: Open Court.

FUKUYAMA, Francis (1992). The end of history and the last man. New York: Free Press.

GORZ, André (1987 [1980]). Adeus ao proletariado: para além do socialismo. Rio de Janeiro: Forense-Universitária.

(1988). Métamorphoses du travail: quète du sens. Critique de la raison économique. Paris: Galilée.

HARTSOCK, Nancy C. M. (1998 [1983]). “The feminist standpoint: developing the ground for a specifically feminist historical materialism", em The feminist standpoint revisited and other essays. Boulder: Westview. HAYEK, Friedrich A. (1990 [1944]). O caminho da servidão. Rio de Janeiro: Instituto Liberal.

HIRSCHMAN, Albert O. (1983 [1982]). De consumidor a cidadão: atividade privada e participação na vida pública. São Paulo: Brasiliense.

HONNETH, Axel (2003 [1992]). Luta por reconhecimento: a gramática moral dos conflitos sociais. São Paulo: Editora 34.

LACLAU, Ernesto \& MOUFFE, Chantal (1987 [1985]). Hegemonía y estrategia socialista: hacia una radicalización de la democracia. Madrid: Siglo Veintiuno.

MACKIE, Gerry (1998). "All men are liars: is democracy meaningless?", em Jon Elster (ed.). Deliberative democracy. Cambridge: Cambridge University Press.

MACPHERSON. C. B. (1978 [1977]). A democracia liberal: origens e evolução. Rio de Janeiro: Zahar.

MALBIN, Michael J. (2009). "Small donors, large donors and the internet: campaign finance reform in New York after Obama”. Paper apresentado no Rockefeller Institute of Government, State University of New York. Albany (NY), 4 de junho.

MANIN, Bernard (1997). The principles of representative government. Cambridge: Cambridge University Press.

MARX, Karl (2010 [1844]). Sobre a questão judaica. São Paulo: Boitempo. MIGUEL, Luis Felipe (2002a). "A democracia domesticada: bases antidemocráticas do pensamento democrático contemporâneo". Dados, v. 45, n. 3 , p. $483-511$. 
(2002b). "As duas lógicas da ação comunicativa: democracia e deliberação no debate contemporâneo". Teoria \& Sociedade, n. 10, p. 104-43.

(2002c). “Os meios de comunicação e a prática política”. Lua Nova, n. $55-6$, p. $155-184$

MILL, John Stuart (1995 [1861]). O governo representativo. São Paulo: Ibrasa. MILLET, Kate (1969). Sexual politics. New York: Ballantine.

MOUFFE, Chantal (1992). "Democratic politics today", em MOUFFE, Chantal (ed.). Dimensions of radical democracy: pluralism, citizenship, community. London: Verso.

(2005 [2000]). The democratic paradox. London: Verso. (2005). On the political. London: Routledge.

NOZICK, Robert (1974). Anarchy, State, and utopia. New York: Basic Books. O'CONNOR, James (1973). The fiscal crisis of the State. New York: St. Martin. OFFE, Claus (1984 [1972]). "Dominação de classe e sistema político. Sobre a seletividade das instituições políticas", em Problemas estruturais do Estado capitalista. Rio de Janeiro: Tempo Brasileiro.

(1997 [1984]). "De quelques contradictions de l'État-providence moderne”, em Les démocraties modernes à l’épreuve. Paris: L'Harmattan. OFFE, Claus \& WIESENTHAL, Helmut (1984 [1980]). "Duas lógicas da ação coletiva: anotações teóricas sobre classe social e forma organizacional", em OFFE, Claus. Problemas estruturais do Estado capitalista. Rio de Janeiro: Tempo Brasileiro.

OKIN, Susan Moller (1989). Justice, gender, and the family. New York: Basic Books.

PATEMAN, Carole (1992 [1970]). Participação e teoria democrática. Rio de Janeiro: Paz e Terra.

(1993 [1988]). O contrato sexual. Rio de Janeiro: Paz e Terra.

PHILLIPS, Anne (1999). Which equalities matter? Cambridge: Polity.

PRZEWORSKI, Adam (1995 [1990]). Estado e economia no capitalismo. Rio de Janeiro: Relume-Dumará.

RAWLS, John (1997 [1971]). Uma teoria da justiça. São Paulo: Martins Fontes. (2000 [1993]). O liberalismo político. São Paulo: Ática. 
RAWLS, John (2001). Justice as fairness: a restatement. Ed. Erin Kelly. Cambridge (MA): Belknap.

RIKER, William H. (1982). Liberalism against populism: a confrontation between the theory of democracy and the theory of social choice. Prospect Heights (IL): Waveland.

ROSANVALLON, Pierre (1995). La nouvelle question sociale: repenser l'État-providence. Paris: Seuil.

ROUSSEAU, Jean-Jacques (1964 [1757]). Du contract social, em Euvres complètes, vol. III. Paris: Gallimard.

SCHUMPETER, Joseph (1942). Capitalism, socialism and democracy. NewYork: Harper and Brothers.

SCOTT, James C. (1985). Weapons of the weak: everyday forms of peasant resistance. New Haven: Yale University Press.

SCOTT, Joan Wallach (1999 [1988]). Gender and the politics of history. Revised edition. New York: Columbia University Press.

SPELMAN, Elizabeth V. (1988). Inessential woman: problems of exclusion in feminist thought. Boston: Beacon Press.

TOCQUEVILLE, Alexis de (1992 [1835]). De la démocratie en Amérique, t. I, em CEuvres, vol. II. Paris: Gallimard.

WOOD, Ellen Meiksins (1995). Democracy against capitalism: renewing historical materialism. Cambridge: Cambridge University Press.

(1998). The retreat from class: a new "true" socialism. With a new introduction by the author. London: Verso.

\section{Resumo:}

A teoria política contemporânea, mesmo em suas vertentes críticas, tende a reduzir a importância das classes sociais. O foco passou às "diferenças" a serem respeitadas e acomodadas no regime democrático. $\mathrm{O}$ artigo argumenta que a desigualdade de classes e os conflitos decorrentes dela permanecem como elementos centrais para a compreensão da dinâmica política das sociedades capitalistas. Elas colocam obstáculos ao aprofundamento da democracia, vinculados à desigualdade material, ao controle da propriedade, à influência sobre o Estado e à socialização diferenciada de trabalhadores e patrões. $\mathrm{O}$ artigo advoga por uma teoria democrática que seja sensível à centralidade da desigualdade de classe, mas sem ignorar a relevância de outras formas de opressão existentes na sociedade. Palavras-chave: democracia, capitalismo, classes sociais, teoria política contemporânea 


\begin{abstract}
:
Even in its critical tendencies, contemporary political theory tends to reduce the importance of social classes. The focus shifted to the "differences" to be respected and accommodated in a democratic regime. The article argues that the inequalities of classes, and the conflicts arising from them, remain central to understanding the political dynamics of capitalist societies. They put obstacles to the deepening of democracy, linked to material inequality, control of the property, influence on the State and differentiated socialization of workers and employers. The article advocates for a democratic theory that is sensitive to the centrality of class inequality, but without ignoring the importance of other forms of oppression in society.
\end{abstract}

Keywords: democracy, capitalism, social classes, contemporary political theory

Recebido em $1^{\circ}$ de junho de 2012.

Aprovado em 20 de agosto de 2012. 